\title{
Understanding Electricity Saving Behavior of Rural Indigenous Communities in La Guajira Department, Colombia
}

\author{
Eder Molina $^{1}$, John E. Candelo-Becerra ${ }^{1, *}$, Edgar Ojeda-Camargo ${ }^{2}$ \\ ${ }^{1}$ Department of Electrical Energy and Automation, Facultad de Minas, Universidad Nacional de Colombia, Sede Medellín, Carrera 80 No. \\ 65 - 223, Campus Robledo, Medellín 050041, Antioquia, Colombia. \\ ${ }^{2}$ Faculty of Engineering, Universidad de la Guajira, Km 5 Via Maicao, Guajira, Colombia.
}

Received 25 January 2018; Accepted 20 December 2018

\begin{abstract}
This paper focuses on identifying how indigenous populations in the upper and middle zones of the La Guajira Department in Colombia save electricity or follow a plan based on an energy policy. To explore this, a survey among seven communities with electricity in the upper and middle zones of La Guajira and a quantitative and observational analysis were conducted. Results show that indigenous communities do not practice a culture of electricity-saving such as, for instance, often failing to turn off idle appliances. In addition, there are neither electricity-saving plans nor energy awareness measures to educate the area's indigenous communities. When comparing the energy consumption of Wayuu communities with that of the country's residential urban dwellers of similar socioeconomic level, few indigenous people using electricity efficiently were found, particularly in terms of lighting and appliance use.
\end{abstract}

Keywords: consumption habits, electricity-saving, energy efficiency, indigenous people, rural communities, La Guajira, Colombia

\section{Introduction}

Energy efficiency leads to a reduction in the consumption of resources and changes any given community's consumption habits. Saving electricity is crucial both for the environment and the technical sustainability of power networks $[1,2]$. This importance is magnified for the country's economy [3, $4]$, particularly for those located in non-interconnected rural areas [5-8].

As seen in La Guajira Department of Colombia, a primary challenge for this type of situation is the annual reduction in the maximum value of electricity subsidized by the state. Determining the electricity saving of rural indigenous communities is, therefore, essential especially in gauging commitment to the country's energy policy plan. Understanding these elements will help the country set more specific and realistic goals, contribute to new and enhanced educational measures on electricity saving for these communities, develop new strategies for improving energy saving, review energy policy requirements, and provide new, optimally adjusted energy systems.

With respect to a rural community's energy supply, various authors have focused on the economic development opportunities surrounding wind energy [9-11]. Other authors have suggested that a state's provision of electric energy can be considered part of a plan to generate wealth and job opportunities while preserving the environment, as recently shown for the inhabitants of the Brazilian Amazon [12]. Other authors have proposed the installation of energy sources in rural areas to solve the problem of energy access in remote areas [13-15]. Moreover, some have proposed a

*E-mail address: jecandelob@unal.edu.co

ISSN: $1791-2377 @ 2018$ Eastern Macedonia and Thrace Institute of Technology. All rights reserved. doi:10.25103/jestr.116.07 diffusion model based on classical diffusion theory, where the adoption rate becomes a function of awareness campaigns and social interaction [16].

Many of these studies, however, explore energy development in indigenous communities in the United States [17]. In Colombia, two researchers conducted a survey of various actors involved in renewable energy systems (RES) projects to identify and analyze the social and political acceptance, market acceptance, and the community acceptance of RES [18]. Finally, other researchers analyzed the viability of photovoltaics (PVs) in northern latitudes as part of the energy supply systems for nomadic camps far from indigenous communities dedicated to reindeer herding [19].

With respect to the use of electricity, one study recognized some household energy consumption patterns in rural areas in South Africa [20]. Another study found that the perceptions of service and facility quality in rural small towns in the U.S. state of Iowa were wholly dependent on a community's social organization [21]. Another study concluded that the electricity consumption of households depends on structural and motivational factors, with predictable patterns of interaction among members that influence their consumption, and that the total electricity saving effort depends on the strength of internalized norms, self-expectations, and factors related to self-efficacy [22]. Another study revealed that providing households with a feedback system that gives information about electricity consumption empowers consumers to take energy-saving measures [23]. A final study analyzed the perspectives of end users and their satisfaction with the quality of service in rural areas [24].

In sum, there are few studies investigating electricitysaving behavior in rural communities, with even fewer focusing on rural indigenous communities. Those that did 
investigate indigenous communities focused on supplying electricity to them, typically by selecting the best renewable energy system [11]. Furthermore, no study on this issue has been performed in Latin America. Therefore, there is no evidence identifying the energy consumption patterns of rural indigenous communities in Latin America, how they might best use or save electricity, and the ways in which electricity service for these communities might be optimized. Consequently, before the installation of electricity services to indigenous communities, government entities must make an effort to create greater awareness to the customers about electricity-saving, as proposed in [22, 23].

This research focuses on identifying how indigenous populations in the upper and middle zones of La Guajira Department in Colombia save electricity or follow a plan based on an energy policy. The methodology is based on descriptive observations, applying surveys, and direct observation of electricity saving behavior within a randomly selected sample population. Data were analyzed and key aspects of user behavior in electrical energy consumption for the different communities described. Monthly electricity consumption of these groups was also studied, noting differences with the rest of the Colombian population, especially urban areas with similar weather conditions and socioeconomic level, where comparable appliances of customers were assumed. The results demonstrated that these communities have problems with electricity-saving measures, with stark consumption differences from those of urban populations.

\section{Methodology}

This section presents the methodology applied in the research, where the population and samples are defined, and how electricity consumption is estimated. In this research, an exploratory descriptive methodology was applied that illustrates the current conditions of population, their access to electricity, and their perceptions of this service in their activities.

\subsection{Population and Sample}

La Guajira Department of Colombia was selected for this study. This department has an area of $20,848 \mathrm{~km}^{2}$ and is divided into three zones: low, medium, and high Guajira [25]. The main municipalities in the middle and upper zones are Manaure, Uribia, Maicao, and Riohacha. All indigenous rural communities are politically associated with those urban jurisdictions.

According to the National Administrative Department of Statistics - DANE [26], there are about 5.1 people per household in La Guajira Department. The number of inhabitants in central and northern Guajira $(219,646)$ was divided by 5.1 , for a total of 43,068 households. Then, probability sampling for this population was applied because all households have the same probability of sample selection. A total of 283 households in seven rural indigenous communities with electricity were asked about the electricity service, consumption, and energy saving plan.

The survey was administered to people living in households of indigenous communities identified as the Wayuu ethnicity without including the survey consumption level of hospitals or rural schools as only residential users were comparable with other urban residential population with similar socioeconomic levels.

\subsection{Estimated Electricity Savings}

Total electricity consumption was estimated by identifying the use of electrical appliances, time of use, and other consumption habits for the target population. Then, the time of use of these appliances, the respective power usage for a 24-hour period, and the daily consumption of different families were obtained. This survey was conducted among the seven communities selected in the sample that had access to the electricity service.

For the population with electricity, a survey to identify behavior leading to the high electricity consumption of households in their daily activities was implemented including the use of appliances and the number and types of light bulbs. These data were compared with answers to the questions about the consumption behavior of these communities and to national consumption levels.

Table 1 shows the questions posed to communities with electricity to gauge their consumption patterns. We also tried to identify the practice of electricity savings, the kinds of appliances used, and the possibility that the respondents knew about the importance of saving electricity. All data were obtained from households.

Table 1. Questions for Indigenous Communities with Electricity

\begin{tabular}{c|l|l}
\hline \multicolumn{1}{c}{ Number } & \multicolumn{1}{c}{ Question } & \multicolumn{1}{c}{ Range } \\
\hline 1 & What is your monthly consumption? & $\begin{array}{l}\text { Low: }(0.0-1.7) \mathrm{kWh} / \mathrm{d} \\
\text { Medium: } 1.8-3.61 \\
\text { High: Greater than 3.61 }\end{array}$ \\
\hline 2 & Which months usually have the highest and lowest consumption rates? & $\begin{array}{l}\text { First semester (January-June) } \\
\text { Second semester (July- } \\
\text { December) }\end{array}$ \\
\hline 3 & Why do you think there is a high consumption rate in general? & $\begin{array}{l}\text { The weather } \\
\text { Family visit } \\
\text { Acquisition of electrical } \\
\text { appliance }\end{array}$ \\
\hline 5 & How would you describe your usage of the electricity service? & $\begin{array}{l}\text { Very good } \\
\text { Good } \\
\text { Regular } \\
\text { Bad } \\
\text { Very bad }\end{array}$ \\
\hline 5 & What are some possible oversights that lead to high consumption rates? & $\begin{array}{l}\text { Cultural aspects } \\
\text { Needs to supply }\end{array}$ \\
\hline
\end{tabular}




\begin{tabular}{c|l|l}
\hline 6 & How many lightbulbs do you use and what is their wattage? & $\begin{array}{l}\text { Lightbulbs }(1,2,3, \ldots, 10) \\
\text { Steps of 100 Watts }(1-100,101- \\
200, \ldots, 901-1000)\end{array}$ \\
\hline 7 & $\begin{array}{l}\text { Is there any information in your community about electricity-saving } \\
\text { measures? }\end{array}$ & $\begin{array}{l}\text { Yes } \\
\text { No }\end{array}$ \\
\hline 8 & Do you save electricity? (If yes, how? If no, why?) & $\begin{array}{l}\text { Yes } \\
\text { No }\end{array}$ \\
\hline 9 & Do you have refrigeration equipment? & $\begin{array}{l}\text { Yes } \\
\text { No }\end{array}$ \\
\hline 10 & What tasks do you need more electricity for? & $\begin{array}{l}\text { Hobbies } \\
\text { Needs }\end{array}$ \\
\hline
\end{tabular}

\section{Results}

\subsection{Consumption Habits}

Table 2 shows the consumption of electricity for those rural indigenous communities that have access to electricity.
These communities are Nazareth-Uribía; Cristin LópezManaure; Paz-Maicao; Villa-Manaure; PesuapaManaure; Santa Rosa-Maicao; and Aujero-Riohacha. The data were obtained as an average consumption of all users surveyed in each group.

Table 2. Electricity Consumption by Time of Day for Rural Indigenous Communities

\begin{tabular}{|c|c|c|c|c|c|c|c|}
\hline \multicolumn{8}{|c|}{ Communities with electricity } \\
\hline & Nazaret & Cristin Lopéz & La Paz & La Villa & Pesuapa & Santa Rosa & Aujero \\
\hline Hour & Load $(\mathrm{kW})$ & $\begin{array}{l}\text { Load } \\
(\mathrm{kW})\end{array}$ & $\begin{array}{l}\text { Load } \\
(\mathrm{kW})\end{array}$ & Load (kW) & $\begin{array}{l}\text { Load } \\
(\mathrm{kW})\end{array}$ & $\begin{array}{l}\text { Load } \\
(\mathrm{kW})\end{array}$ & $\begin{array}{l}\text { Load } \\
(\mathrm{kW})\end{array}$ \\
\hline 00:00 - 01:00 & 0.032 & 0.06 & 0.053 & 0.048 & 0.014 & 0.013 & 0.069 \\
\hline 01:00 - 02:00 & 0.043 & 0.093 & 0.071 & 0.055 & 0.031 & 0.053 & 0.096 \\
\hline 02:00 - 03:00 & 0.045 & 0.12 & 0.081 & 0.048 & 0.049 & 0.068 & 0.135 \\
\hline 03:00 - 04:00 & 0.068 & 0.178 & 0.087 & 0.055 & 0.059 & 0.069 & 0.154 \\
\hline 04:00 - 05:00 & 0.167 & 0.231 & 0.201 & 0.169 & 0.181 & 0.181 & 0.209 \\
\hline 05:00 - 06:00 & 0.181 & 0.299 & 0.221 & 0.194 & 0.261 & 0.2 & 0.251 \\
\hline 06:00 - 07:00 & 0.268 & 0.313 & 0.27 & 0.267 & 0.293 & 0.247 & 0.303 \\
\hline 07:00 - 08:00 & 0.277 & 0.296 & 0.288 & 0.279 & 0.281 & 0.287 & 0.351 \\
\hline 08:00 - 09:00 & 0.154 & 0.13 & 0.165 & 0.16 & 0.13 & 0.166 & 0.271 \\
\hline 09:00 - 10:00 & 0.136 & 0.171 & 0.163 & 0.154 & 0.179 & 0.153 & 0.188 \\
\hline $10: 00-11: 00$ & 0.131 & 0.139 & 0.139 & 0.131 & 0.143 & 0.144 & 0.151 \\
\hline 11:00 - 12:00 & 0.227 & 0.227 & 0.227 & 0.228 & 0.289 & 0.234 & 0.271 \\
\hline $12: 00-13: 00$ & 0.279 & 0.29 & 0.307 & 0.289 & 0.276 & 0.3 & 0.354 \\
\hline $13: 00-14: 00$ & 0.242 & 0.27 & 0.275 & 0.265 & 0.267 & 0.235 & 0.303 \\
\hline 14:00 - 15:00 & 0.165 & 0.178 & 0.171 & 0.157 & 0.24 & 0.156 & 0.212 \\
\hline $15: 00-16: 00$ & 0.137 & 0.14 & 0.154 & 0.132 & 0.232 & 0.164 & 0.158 \\
\hline $16: 00-17: 00$ & 0.178 & 0.18 & 0.191 & 0.172 & 0.3 & 0.194 & 0.214 \\
\hline 17:00 - 18:00 & 0.258 & 0.278 & 0.296 & 0.256 & 0.333 & 0.277 & 0.289 \\
\hline 18:00 - 19:00 & 0.285 & 0.311 & 0.323 & 0.297 & 0.367 & 0.304 & 0.352 \\
\hline 19:00 - 20:00 & 0.273 & 0.29 & 0.289 & 0.27 & 0.378 & 0.274 & 0.307 \\
\hline $20: 00-21: 00$ & 0.229 & 0.298 & 0.252 & 0.235 & 0.334 & 0.211 & 0.288 \\
\hline $21: 00-22: 00$ & 0.143 & 0.13 & 0.146 & 0.114 & 0.21 & 0.145 & 0.212 \\
\hline $22: 00-23: 00$ & 0.087 & 0.055 & 0.07 & 0.059 & 0.134 & 0.066 & 0.097 \\
\hline 23:00 - 00:00 & 0.041 & 0.019 & 0.051 & 0.026 & 0.0012 & 0.035 & 0.061 \\
\hline Total & 4.046 & 4.696 & 4.491 & 4.06 & 4.9822 & 4.176 & 5.296 \\
\hline
\end{tabular}

The indigenous community of Aujero consumes electricity above the average rate of several other municipalities; this fact identifies important consumption habits among these indigenous communities along with variations from one community to another. Notably, the consumption peaks are always at the same time in the surveyed communities, even though electricity rates change from one community to another. The indigenous community of Aujero has the highest consumption peak until 1500 hours, when it is surpassed by Pesuapa. All these indigenous communities have consumption peaks in three periods instead of two-as in the urban population-i.e., consumption peaks between 0600 and 0800 hours, between
1200 and 1400 hours, and between 1800 and 2100 hours. Identifying communities with estimated electricity consumption near or above the subsistence limits allows us to identify the need for a new energy efficiency plan and to create awareness among these populations about electricity saving. Additionally, this comparison is useful for determining whether sustainable electricity production projects can be implemented to improve the social development of these communities [27-29].

\subsection{Comparisons of Electricity Consumption}

Table 3 shows the comparison of average power consumption of rural indigenous communities and the urban 
population. All information was obtained from population surveys conducted during this research, with information about urban areas obtained from [30]. The differences in electricity consumption reveal the need for plans to use home appliances efficiently. Communities with a high consumption of electricity were also identified for the potential implementation of electricity-saving plans.

Table 3. Average Power Consumption of Rural Indigenous Communities and Urban Population

\begin{tabular}{l|c|l|l|l}
\hline \multicolumn{2}{c}{ Rural indigenous communities } & \multicolumn{3}{c}{ Urban Population } \\
\hline & $\begin{array}{l}\text { Electricity consumption per } \\
\text { month (KWh - Month) }\end{array}$ & \multicolumn{2}{|l}{$\begin{array}{l}\text { Electricity consumption per month } \\
\text { (KWh - Month) }\end{array}$} \\
\hline Manaure & 145.1 & Pasto & 147.6 \\
\hline Maicao & 127.2 & Medellín & 110.9 \\
\hline Uribía & 121.3 & Barranquilla & 153.9 \\
\hline Riohacha & 158.8 & Bogotá & 176.2 & \\
\hline
\end{tabular}

It is surprising how communities near the municipality of Riohacha have higher energy consumption than cities with the same climate, with the relevant comparator being the city of Barranquilla. Notably, as the second-most populous city in the country, Medellín has lower levels of consumption than all these communities. This is an important observation because these rural communities tend not to have high-consumption appliances, making it even more important for these populations to receive education on the culture of energy-saving, either by energy companies or the government itself. They need to learn these new consumption habits, which can become the basis for new projects that have the ultimate purpose of finding a renewable energy source.

Table 4 shows the comparison of the use of electrical appliances in indigenous communities and urban communities. The refrigerator is the main electrical appliance used by indigenous communities followed by the television and lighting. Therefore, urban communities experiencing the same weather conditions use fans in a very different way from indigenous communities and infer that these indigenous communities do not iron-possibly because they do not value the look of pressed clothes.
Table 4. Use of Electrical Appliances in Indigenous and Urban Communities

\begin{tabular}{l|c|c}
\hline \multicolumn{3}{c}{ Percentage of appliance use } \\
\hline $\begin{array}{l}\text { Household } \\
\text { appliance }\end{array}$ & $\begin{array}{l}\text { Rural indigenous } \\
\text { communities }\end{array}$ & $\begin{array}{l}\text { Urban } \\
\text { Population }\end{array}$ \\
\hline Lighting & $24 \%$ & $16 \%$ \\
TV & $25 \%$ & $8 \%$ \\
Refrigerator & $25 \%$ & $39 \%$ \\
Laundry & $7 \%$ & $2 \%$ \\
machine & & \\
Fans & $3 \%$ & $28 \%$ \\
Cooking & $4 \%$ & $0 \%$ \\
Others & $12 \%$ & $7 \%$ \\
\hline
\end{tabular}

Figure 1 presents the number and types of light bulbs these communities used for lighting. The vast majority of indigenous populations do not use energy-saving light bulbs. The population uses an average of four to six light bulbs per household. When multiplied by the power consumed by each light bulb, this does not represent high consumption, yet a change is required in the type of light bulb to guarantee greater energy efficiency.

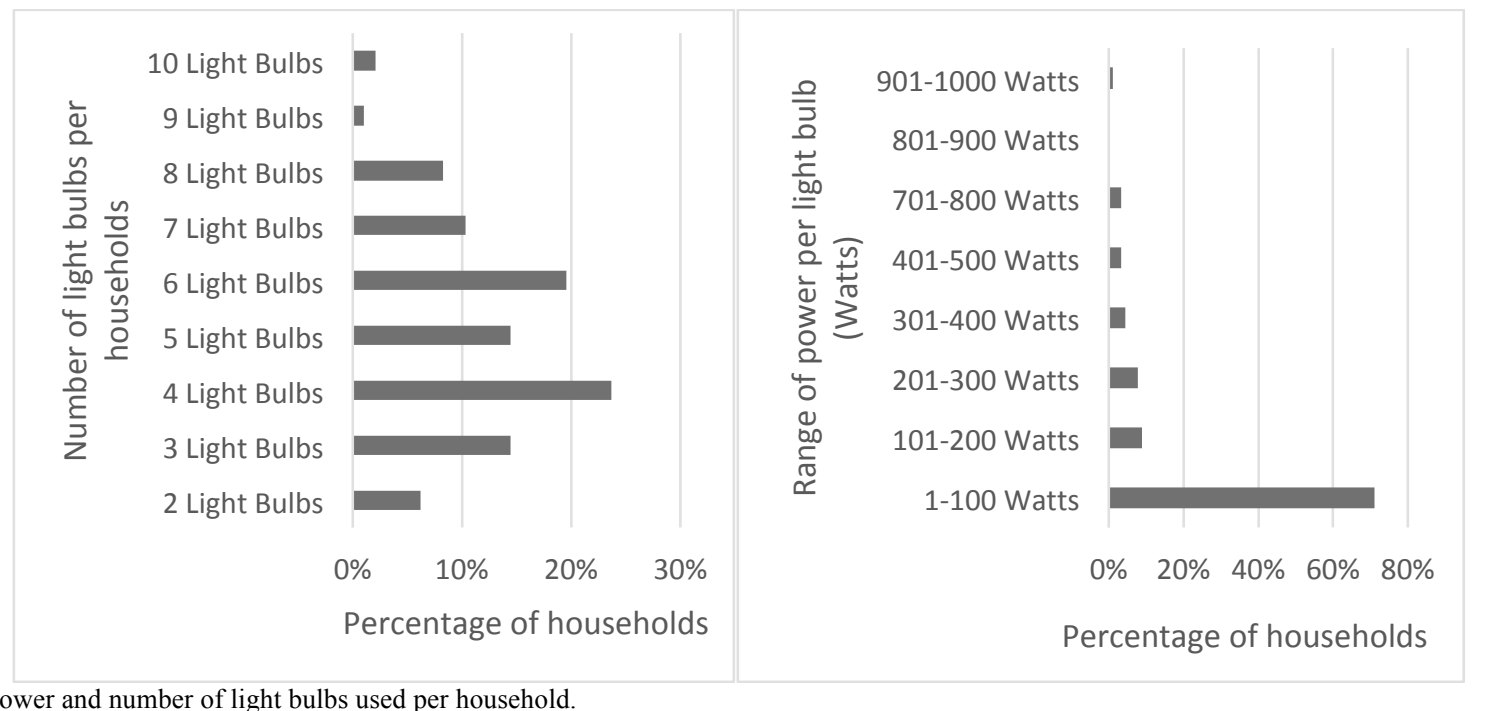

Fig. 1. Power and number of light bulbs used per household.

\subsection{Energy-saving plans}

More than $90 \%$ of the population stated that they do not know anything about saving electricity. This situation can be improved with pedagogic methods and publicity to create awareness on electricity-saving that has the potential to change the mindset of these indigenous communities [31].
As illustrated in Fig. 2, a significant number of people are not compromised with energy-saving plans. 


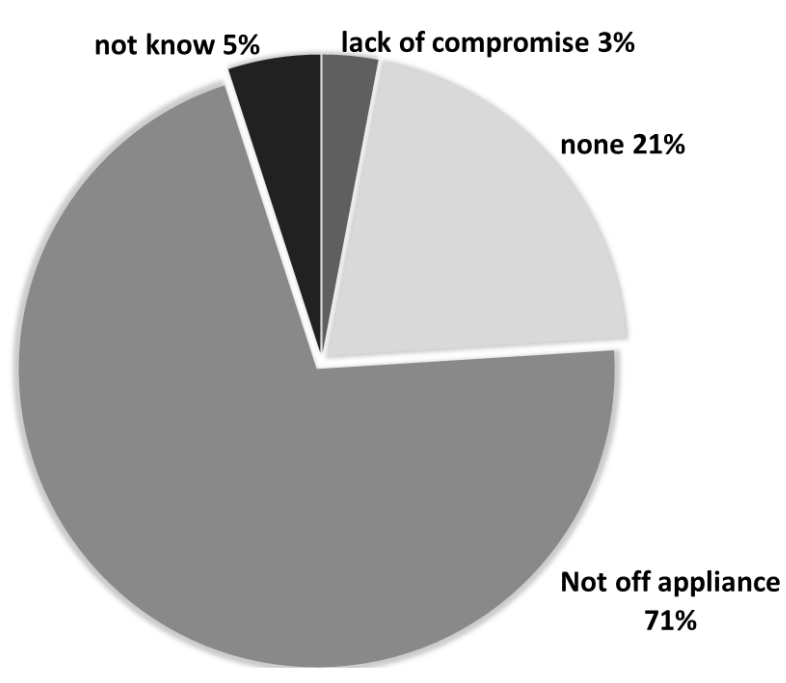

Fig. 2. Percentage of people compromised with energy-saving plans.

People in indigenous communities were asked about the role that negligence might play in high energy consumption. Most answered that they did not turn off or unplug appliances because they were not aware that even after shutdown some appliances continue to consume energy. This demonstrates the necessity of campaigns on energy efficiency to create an electricity-saving culture in these communities. Through this research, it was possible to observe that rural indigenous communities living in the upper and middle zone of La Guajira were not aware of the importance of electricity-saving policies primarily because their energy supplier does not release information promoting or explaining such policies. Fig. 3 shows that a large percentage of people in these communities simply do not know about energy-saving practices.

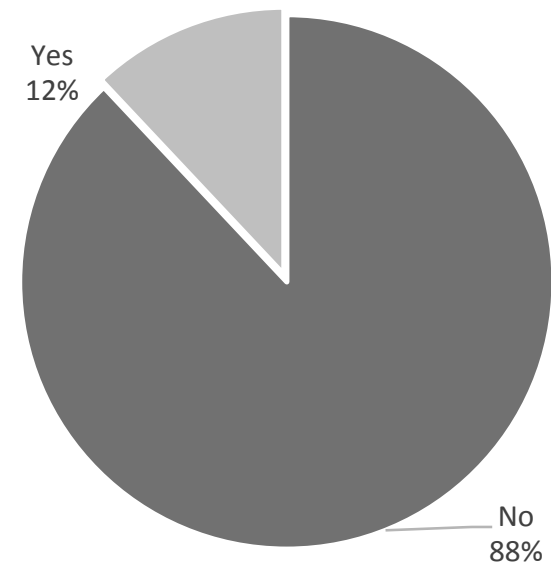

Fig. 3. Percentage of people that know about energy-saving practices.

\section{Discussion}

Shortcomings in education about electricity-saving were found in the indigenous communities of middle and upper La Guajira, particularly through their misuse of certain appliances along with a lack of unawareness that their own habits generate more consumption [23, 32]. This includes, for example, failing to unplug appliances when they are not in use. All of these awareness will allow the creation of new programs that enhance the energy consumption of indigenous communities [33, 34].

The Aujero community showed a higher consumption of energy per month than the indigenous communities from Maicao or Manaure. In addition, consumption rates of this population are above those of populations living in cities with more industrial development and similar weather conditions (as in the case of Barranquilla). Some indigenous populations have higher power consumption than the lowest socio-economic strata of the city of Medellín. An apparent reason for this may be that indigenous communities do not use electrical services efficiently, potentially because they lack electricity-saving habits.

The increase in energy consumption of indigenous communities in the upper and middle zones of La Guajira is directly related to its use for refrigeration (compared with cities with the same weather conditions), lighting, and the use of appliances, especially TV. Consumption rates are lower than in other places in general but when compared with lighting and TV use, their rates are much higher. Lighting is a particularly noteworthy topic because consumption rates are higher in these rural communities than in large cities. As such, indigenous communities require urgent reforms and new energy efficiency strategies and policies to reduce consumption in relation to the use of lighting and appliances as earlier proposed by $[35,36]$.

As a result, it is imperative for electrical companies to implement pedagogical training interventions and design electricity-saving plans to promote an energy-saving culture among these communities. The results of the survey found that most indigenous people have never seen a television advertisement about saving electricity, a fact that has been previously confirmed for other cultures [37]. Most indigenous people do not know about electricity policies and this may be the main reason why they do not unplug their appliances and continue to use high-consumption lightbulbs above $100 \mathrm{~W}$.

These results indicate that indigenous communities require continuous support that can be provided through public talks on saving electricity and on how new energy plans should be executed as has been done for other populations [22, 23]. Many community members are unaware of this support, which has the potential to improve their quality of life [38] even though such measures have never previously been implemented with any indigenous community. Furthermore, community acceptance plays a decisive role in the design of future energy projects, including the use of RES to optimize consumption [10,39].

The indigenous communities surveyed tend not to make efficient use of their electrical service, which only underlines the need to implement pedagogic classes on electricitysaving topics. In the future, Colombian law may well require the design of energy-generation projects using alternative energy sources like solar energy, wind power plants, or the interconnection of different generation systems [10, 40, 41]. Energy-saving plans would help optimize load consumption and, furthermore, as proposed by [13], it would help optimize generation systems and their installation in rural areas. Before providing electricity services in indigenous communities, it is necessary to design a special energysaving plan in order to design optimal energy systems.

In analyzing the data from indigenous communities on their electricity use, we observed the high consumption for lighting. These indigenous communities use light bulbs that consume up to five times more power than more modern bulbs; thus, it is essential to change the lightbulbs these 
indigenous communities use and to promote an energysaving mindset in this population [22]. Government entities must provide guidance and advertisements to promote electricity-saving. This study can be applied to new electricity users among indigenous populations, but much more work is required in the preparation of pedagogic material in the field of energy efficiency along with the generation of awareness of this matter throughout the entire community.

\section{Conclusions}

This paper focused on identifying how indigenous populations in the upper and middle zones of the La Guajira Department in Colombia save electricity or follow a plan based on an energy policy. From the results obtained in the research, it can be inferred that most of the indigenous population in the Colombian Guajira do not manage the culture of energy efficiency in terms of electricity consumption. Additionally, their consumption behavior does not follow a current regional or national-level energy policy plan. Some fail to turn off idle appliances when they do not need them and there are no energy awareness measures to educate indigenous communities. Comparison of electricity consumption of Wayuu communities and electricity consumption the country's residential urban dwellers with similar socioeconomic level revealed that few indigenous people use electricity efficiently as shown by the hours of use of lighting and some appliances.
Although electricity is used to perform basic activities, there is little justification for the high consumption rates of some communities, particularly those that exceed consumption rates of urban populations in low socioeconomic strata. In the last few years, the electricity consumption threshold in Colombia's energy policy has been reduced, which is now a concern for indigenous households that are over the minimum value subsided. To counteract this trend, the inefficient use of electricity services in rural indigenous communities must be managed by government entities to avoid affecting their economies in future. Our results are potentially useful for the design and future implementation of systems not already connected to the grid, such as generation systems based on solar or wind energy. These mechanisms may address the lack of access to electricity and improve the quality of life for these communities. Therefore, it is necessary to implement pedagogical measures to promote electricity saving. Future research should analyze the economic viability of possible cooperation between manufacturers and government to eliminate older lighting systems, many of which date to the last century. Our research also noted the lack of advertising around electricity-saving and this may be a primary cause of higher consumption rates.

This is an Open Access article distributed under the terms of the Creative Commons Attribution License

\section{References}

1. C. S. Psomopoulos, I. Skoula, C. Karras, A. Chatzimpiros, and M. Chionidis, Electricity savings and $\mathrm{CO} 2$ emissions reduction in buildings sector: How important the network losses are in the calculation?, Energy, 35(1), pp. 485-490 (2010).

2. R. Harmsen and W. Graus, How much $\mathrm{CO} 2$ emissions do we reduce by saving electricity? A focus on methods, Energy Policy, 60, pp. 803-812 (2013).

3. K. Ek and P. Söderholm, The devil is in the details: Household electricity saving behavior and the role of information, Energy Policy, 38(3), pp. 1578-1587 (2010).

4. M. Lenzen, M. Krishnapillai, D. Talagi, J. Quintal, D. Quintal, R. Grant, S. Abraham, C. Ehmes, and J. Murray, Cultural and socioeconomic determinants of energy consumption on small remote islands, Nat. Resour. Forum, 38(1), pp. 27-46 (2014).

5. Consorcio Energético: CORPOEMA, Plan de desarrollo para las fuentes no convencionales de energía en Colombia, 1, pp. 1-382 (2010).

6. Departamento Administrativo de Planeación de La Guajira, Tercer Informe: La seguridad alimentaria de la media y alta Guajira (2014).

7. E. W. Mugi-Ngenga, M. W. Mucheru-Muna, J. N. Mugwe, F. K. Ngetich, F. S. Mairura, and D. N. Mugendi, Household's socioeconomic factors influencing the level of adaptation to climate variability in the dry zones of Eastern Kenya, J. Rural Stud., 43, pp. 49-60 (2016).

8. A. Gilbert, Helping the poor through housing subsidies: lessons from Chile, Colombia and South Africa, Habitat Int., 28(1), pp. 13-40 (2004).

9. M. Munday, G. Bristow, and R. Cowell, Wind farms in rural areas: How far do community benefits from wind farms represent a local economic development opportunity?, J. Rural Stud., 27(1), pp. 1-12 (2011).

10. C. Goodbody, E. Walsh, K. P. McDonnell, and P. Owende, Regional integration of renewable energy systems in Ireland The role of hybrid energy systems for small communities, Int. J. Electr. Power Energy Syst., 44(1), pp. 713-720 (2013).
11. M. E. Huesca-Pérez, C. Sheinbaum-Pardo, and J. Köppel, Social implications of siting wind energy in a disadvantaged region The case of the Isthmus of Tehuantepec, Mexico, Renew. Sustain. Energy Rev., 58, pp. 952-965 (2016).

12. C. S. Andrade, L. P. Rosa, and N. F. da Silva, Generation of electric energy in isolated rural communities in the Amazon Region a proposal for the autonomy and sustainability of the local populations, Renew. Sustain. Energy Rev., 15(1), pp. 493-503 (2011).

13. E. E. Gaona, C. L. Trujillo, and J. A. Guacaneme, Rural microgrids and its potential application in Colombia, Renew. Sustain. Energy Rev., 51, pp. 125-137 (2015).

14. S. Nie, X.-P. Fu, P. Li, F. Gao, C.-D. Ding, H. Yu, and C.-S. Wang, Analysis of the impact of DG on distribution network reconfiguration using OpenDSS, in IEEE PES Innovative Smart Grid Technologies, pp. 1-5 (2012).

15. L. Byrnes, C. Brown, L. Wagner, and J. Foster, Reviewing the viability of renewable energy in community electrification: The case of remote Western Australian communities, Renew. Sustain. Energy Rev., 59, pp. 470-481 (2016).

16. A. A. Radomes and S. Arango, Renewable energy technology diffusion: an analysis of photovoltaic-system support schemes in Medellín, Colombia, J. Clean. Prod., 92, pp. 152-161 (2015).

17. L. Necefer, G. Wong-Parodi, P. Jaramillo, and M. J. Small, Energy development and Native Americans: Values and beliefs about energy from the Navajo Nation, Energy Res. Soc. Sci., 7, pp. 1$11(2015)$.

18. A. M. Rosso-Cerón and V. Kafarov, Barriers to social acceptance of renewable energy systems in Colombia, Curr. Opin. Chem. Eng., 10, pp. 103-110 (2015).

19. S. V. Obydenkova and J. M. Pearce, Technical viability of mobile solar photovoltaic systems for indigenous nomadic communities in northern latitudes, Renew. Energy, 89, pp. 253-267 (2016).

20. M. Davis, Rural household energy consumption: The effects of access to electricity-evidence from South Africa, Energy Policy, 26(3), pp. 207-217 (1998). 
21. L. Wright Morton, Small Town Services and Facilities: The Influence of Social Networks and Civic Structure on Perceptions of Quality, City Community, 2(2), pp. 102-120 (2003).

22. J. Thøgersen and A. Grønhøj, Electricity saving in households-A social cognitive approach, Energy Policy, 38(12), pp. 7732-7743 (2010).

23. A. Grønhøj and J. Thøgersen, Feedback on household electricity consumption: learning and social influence processes, Int. J. Consum. Stud., Vol. 35, No. 2, pp. 138-145, Mar. 2011.

24. C.-W. Shyu, End-users' experiences with electricity supply from stand-alone mini-grid solar PV power stations in rural areas of western China, Energy Sustain. Dev., 17(4), pp. 391-400 (2013).

25. C. Puerta Silva, Roles y estrategias de los gobiernos indígenas en el sistema de salud colombiano, Rev. Colomb. Antropol., 40(41), pp. 85-125 (2004).

26. DANE, Boletin Censo General DANE 2005, pp. 1-6 (2006).

27. A. K. Akella, R. P. Saini, and M. P. Sharma, Social, economical and environmental impacts of renewable energy systems, Renew. Energy, 34(2), pp. 390-396 (2009).

28. J. Coria and E. Calfucura, Ecotourism and the development of indigenous communities: The good, the bad, and the ugly, Ecol. Econ., 73, pp. 47-55 (2012).

29. L. R. Valer, A. Mocelin, R. Zilles, E. Moura, and A. C. S. Nascimento, Assessment of socioeconomic impacts of access to electricity in Brazilian Amazon: case study in two communities in Mamirauá Reserve, Energy Sustain. Dev., 20, pp. 58-65 (2014).

30. Universidad Nacional de Colombia and Unidad de Planeación Minero Energética UPME, Determinación del consumo final de energía en los sectores residencial urbano y comercial y determinación para equipos domésticos de energía eléctrica y gas, Bogotá, Colombia (2006).

31. S. Hori, M. Shinozaki, D. Nogata, and T. Fujita, The role of CSR in promoting companies' energy-saving actions in two Asian cities, Energy Policy, 69, pp. 116-121 (2014).
32. J. Kleinschafer and M. Morrison, Household norms and their role in reducing household electricity consumption, Int. J. Consum. Stud., 38(1), pp. 75-81 (2014).

33. M. D. Sahakian and J. K. Steinberger, Energy Reduction Through a Deeper Understanding of Household Consumption, J. Ind. Ecol., 15(1), pp. 31-48 (2011).

34. R. Ozaki, Adopting sustainable innovation: what makes consumers sign up to green electricity?, Bus. Strateg. Environ., 20(1), pp. 117 (2011).

35. M. Bernstein and M. Collins, Saving energy through better information: a new energy paradigm?, Contemp. Econ. Policy, 32(1), pp. 219-229 (2014)

36. R. Shwom and J. A. Lorenzen, Changing household consumption to address climate change: social scientific insights and challenges, Wiley Interdiscip. Rev. Clim. Chang., 3(5), pp. 379-395 (2012).

37. S. Z. Attari, M. L. DeKay, C. I. Davidson, and W. Bruine de Bruin, Public perceptions of energy consumption and savings, Proc. Natl. Acad. Sci., 107(37), pp. 16054-16059 (2010).

38. J. Martins, The Impact of the Use of Energy Sources on the Quality of Life of Poor Communities, Soc. Indic. Res., 72(3), pp. 373402 (2005).

39. S. Ashok, Optimised model for community-based hybrid energy system, Renew. Energy, 32(7), pp. 1155-1164 (2007).

40. A. Prada Blanco, M. X. Vázquez Rodríguez, and M. Soliño Millán, Percepción social sobre generación de electricidad con fuentes de energía renovables en Galicia, Rev. Galega Econ., 16(1), pp. 120 (2007).

41. M. Hoogwijk, B. de Vries, and W. Turkenburg, Assessment of the global and regional geographical, technical and economic potential of onshore wind energy, Energy Econ., 26, pp. 889-919 (2004). 